\title{
Radix clematidis extract inhibits TPA-induced MMP-9 expression by suppressing NF-кB activation in MCF-7 human breast cancer cells
}

\author{
EUN-MI NOH* ${ }^{*}$ YOUNG-RAE LEE*, HYUN HUR and JONG-SUK KIM \\ Department of Biochemistry and Institute for Medical Sciences, Chonbuk National University Medical School, \\ Jeonju, Jeonbuk 560-182, Republic of Korea
}

Received March 15, 2011; Accepted July 5, 2011

DOI: $10.3892 / \mathrm{mmr} .2011 .532$

\begin{abstract}
Matrix metalloproteinase-9 (MMP-9), which degrades the extracellular matrix (ECM), plays an important role in breast cancer pathogenesis. Previously, we reported that the Radix clematidis extract (RCE) inhibits MMP expression by suppressing the nuclear factor- $\kappa \mathrm{B}(\mathrm{NF}-\mathrm{\kappa B})$ pathway. The purpose of the present study was to investigate the effects of RCE on 12-O-tetradecanoyl phorbol-13-acetate (TPA)induced MMP-9 expression and cell invasion in MCF-7 cells. The toxicity of RCE was determined by MTT assay. MMP-9 expression was determined by real-time PCR, zymography and Western blot analysis. NF- $\mathrm{\kappa B}$ activation was assayed by electrophoretic mobility shift assay (EMSA). Results showed that the expression of MMP-9 and cell invasion in response to TPA was increased, whereas TPA-induced MMP-9 expression and cell invasion was decreased by RCE. Moreover, RCE suppressed NF- $\kappa \mathrm{B}$ activation in TPA-treated MCF-7 cells. Thus, RCE is a potent inhibitor of TPA-induced MMP-9 expression and markedly blocks the NF- $\mathrm{KB}$ pathway in MCF-7 cells.
\end{abstract}

\section{Introduction}

Radix clematidis is the name given to the root of Clematis florida $T_{H U N B}$, a member of the Ranuncluaceae family. Radix clematidis is commonly used in traditional Chinese medicine for rheumatoid arthritis, gout, lower back and limb pain, strokes, headaches, congestion, promotion of urination, menstrual complications, and tonsillitis. Radix clematidis extract (RCE) possess high concentrations of pharmaceutical active isoflavonoids, including quercetin and kaempferol (1). RCE has been

Correspondence to: Dr Hyun Hur and Dr Jong-Suk Kim, Department of Biochemistry and Institute for Medical Sciences, Chonbuk National University, Jeonju, Jeonbuk 560-182, Republic of Korea

E-mail: hhyun1305@yahoo.co.kr; jsukim@jbnu.ac.kr

*Contributed equally

Key words: Radix clematidis, matrixmetalloproteinase-9, metastasis, invasion, nuclear factor- $\kappa \mathrm{B}, \mathrm{MCF}-7$ found to induce suppression of the nuclear factor- $\kappa \mathrm{B}(\mathrm{NF}-\kappa \mathrm{B})$ signaling pathway $(2,3)$. It is well known that NF- $\kappa \mathrm{B}$ is a transcription factor of significance to the regulation of MMP-9, as the promoter of matrix metalloproteinase-9 (MMP-9) gene contains binding sites for NF- $\mathrm{KB}$ (4). Therefore, it was hypothesized that RCE possesses anticancer properties that inhibit cell invasion.

Breast cancer is a leading cause of malignancy-related deaths in females (5). Most cases of breast cancer-related death are caused by distant metastasis to areas including the bone, lung, liver, kidney, thyroid and brain (6). Invasion and metastasis are the fundamental characteristics and major causes of morbidity and mortality in breast cancer patients. These processes require degradation of the extracellular matrix (ECM), which provides biochemical and mechanical barriers to cell movement in cancer cells (7). The ECM consists of type IV collagen, laminin, heparan sulfate proteoglycan, nidogen and fibronectin (8). ECM degradation requires extracellular proteinases, of which the matrix metalloproteinases (MMPs) have been shown to play a critical role in breast cancer.

MMPs are a family of zinc- and calcium-dependent endopeptidases, constituting four subclasses based on substrate, including collagenases, gelatinases, stromelysins and membrane-associated MMPs. MMP-9 is reported to be a key enzyme for degrading type IV collagen, which is a major component of the basement membrane. Elevated MMP-9 levels are functionally linked to elevated metastasis in a number of tumors, including those of the brain (9), prostate (10), bladder (11) and breast $(12,13)$. Several mechanisms regulate MMP-9 activity, including gene transcription, proenzyme activation, and endogenous inhibitors such as tissue inhibitors of metalloproteinases (TIMPs). A variety of stimuli, including cytokines and phorbol ester, stimulate MMP-9 synthesis and secretion during various pathological processes such as tumor invasion, atherosclerosis, inflammation, and rheumatoid arthritis. MMP-2, on the other hand, is usually expressed constitutively $(13,14)$. Cytokine and 12-O-tetradecanoyl phorbol-13-acetate (TPA) treatments are capable of inducing MMP-9 expression via the activation of transcription factors such as NF- $x \mathrm{~B}$ and activator protein-1 (AP-1) (15-17). Consequently, inhibiting MMP-9 expression and/or its upstream regulatory pathways is critical to the treatment of malignant tumors, including breast carcinoma. 
The purpose of this study was to examine the effects of RCE on TPA-induced MMP-9 expression and cell invasion in MCF-7 cells, a breast cancer cell line.

\section{Materials and methods}

Cells and materials. MCF-7 cells were obtained from the American Type Culture Collection (Manassas, VA, USA). Cells were cultured in Dulbecco's modified Eagle's medium (DMEM) supplemented with $10 \%$ fetal bovine serum (FBS) and $1 \%$ antibiotics at $37^{\circ} \mathrm{C}$ in a $5 \% \mathrm{CO}_{2}$ incubator. $12-O$-tetradecanoyl phorbol-13-acetate (TPA) and 3-(4,5-dimethyl-thiazol-2-yl)2,5-diphenyl-tetrazolium bromide (MTT), dimethyl sulfoxide (DMSO) and anti- $\beta$-actin antibody were obtained from Sigma (St. Louis, MO, USA). Primary antibodies for MMP-9, p50, p65, PCNA, and horseradish peroxidase (HRP)-conjugated $\mathrm{IgG}$ were purchased from Santa Cruz Biotechnology (Santa Cruz, CA, USA). [a32-P]dCTP was obtained from Amersham (Buckinghamshire, UK). High glucose-containing DMEM, FBS and phosphate-buffered saline (PBS) were obtained from Gibco-BRL (Gaithersburg, ME, USA).

Preparation of RCE. Radix clematidis was obtained from Wonkwang Oriental Medical Hospital in Iksan, Jeonbuk, Korea and its identity was confirmed by Dr H.-J. Song, Keeper of the Herbarium. Voucher samples were preserved for reference in the Herbarium of the Department of Physiology, School of Oriental Medicine, Wonkwang University. (Omcphy, 2005-58). A total amount of $200 \mathrm{~g}$ of Radix clematidis was then ground and extracted in boiling water for $4 \mathrm{~h}$. The extract was centrifuged at $3,000 \mathrm{x} \mathrm{g}$ for $20 \mathrm{~min}$. The supernatant was concentrated to $200 \mathrm{ml}$ under reduced pressure and then freeze-dried to $20.4 \mathrm{~g}$. The sterile extract was then maintained at $-70^{\circ} \mathrm{C}$ until use.

MTT assay. The effect of RCE on MCF-7 cell viability was determined using an MTT assay. Briefly, cells were seeded to $2 \times 10^{4} /$ well and allowed to attach. After $24 \mathrm{~h}$, cells were treated with various RCE concentrations $(10,50,100$ and $200 \mu \mathrm{g})$. After incubation for $24 \mathrm{~h}$, cells were washed with PBS, MTT $(0.5 \mathrm{mg} / \mathrm{ml}$ PBS $)$ was added to each well and the plates were incubated at $37^{\circ} \mathrm{C}$ for 30 min.Formazan crystals were dissolved with DMSO (100 $\mu \mathrm{l} /$ well $)$ and detected at $570 \mathrm{~nm}$ using a microplate reader (Model 3550, Bio-Rad, Richmond, CA, USA).

Western blot analysis. MCF-7 cells $\left(5 \times 10^{5}\right)$ were treated with RCE (50 and $100 \mu \mathrm{g})$ and TPA (100 nM) for $24 \mathrm{~h}$. Cells were lysed with ice-cold M-PER ${ }^{\circledR}$ mammalian protein extraction reagent (Pierce Biotechnology, Rockford, IL, USA). The protein concentration in the lysate was determined using the Bradford method (18). Samples $(20 \mu \mathrm{g})$ were separated by sodium dodecyl sulfate polyacrylamide gel electrophoresis (SDS-PAGE) with $10 \%$ acrylamide, and transferred to Hybond ${ }^{\mathrm{TM}}$-PVDF membranes using Western blot apparatus. The PVDF membranes were blocked with 5\% skim milk and incubated overnight with $1 \mu \mathrm{g} / \mathrm{ml}$ primary antibodies for MMP-9, $\beta$-actin, p50, p65, or PCNA. HRP-conjugated IgG was used as a secondary antibody. Protein expression levels were determined by signal analysis using an image analyzer (Fuji-Film, Japan).

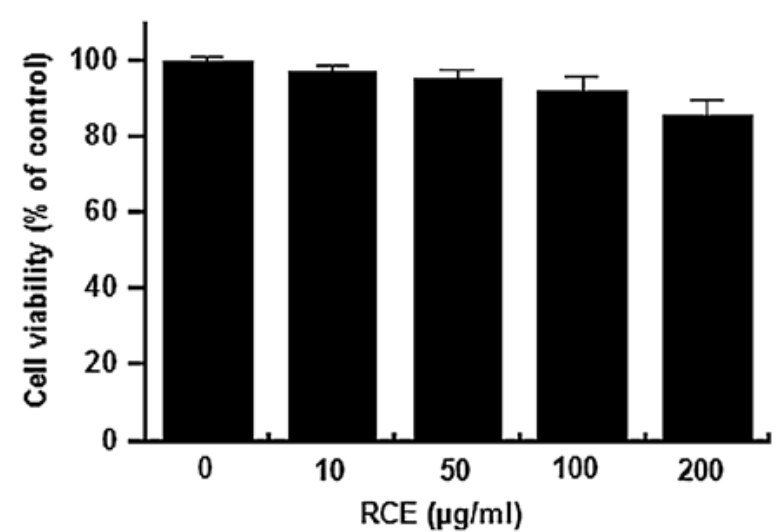

Figure 1. Effects of RCE on cell viability of MCF-7 cells. To test the cytotoxicity of RCE, cells were cultured in 96-well plates until $70 \%$ confluence was achieved and various concentrations of RCE were added to cells for $24 \mathrm{~h}$. MTT assay was used to detect cell viability. The optical density value of the control was regarded as $100 \%$. Data points are the means \pm SEM of three independent experiments.

Gelatin zymography assay. Conditioned media were collected after $24 \mathrm{~h}$ stimulation, mixed with non-reducing sample buffer, and electrophoresed in a polyacrylamide gel containing $0.1 \%(\mathrm{w} / \mathrm{v})$ gelatin. The gel was washed at room temperature for $30 \mathrm{~min}$ with $2.5 \%$ Triton X-100 solution, and subsequently incubated at $37^{\circ} \mathrm{C}$ for $16 \mathrm{~h}$ in $5 \mathrm{mM} \mathrm{CaCl}_{2}$, $0.02 \% \mathrm{Brij}$, and $50 \mathrm{mM}$ Tris- $\mathrm{HCl}(\mathrm{pH} 7.5)$. The gel was stained for 30 min with $0.25 \%$ (w/v) Coomassie brilliant blue in $40 \%(\mathrm{v} / \mathrm{v})$ methanol $/ 7 \%(\mathrm{v} / \mathrm{v})$ acetic acid and visualized on an image analyzer (Fuji-Film, Japan). Proteolysis was imaged as a white zone in a dark blue field. Densitometric analysis was performed using Multi Gauge Image Analysis software (Fuji-Film).

Quantitative real-time PCR assay. Total RNA was extracted from cells using a FastPure ${ }^{\mathrm{TM}}$ RNA kit (Takara, Shiga, Japan). The RNA concentration and purity were determined by absorbance at 260/280 nm. cDNA was synthesized from $1 \mu \mathrm{g}$ total RNA using a PrimeScript ${ }^{\mathrm{TM}}$ RT reagent kit (Takara). MMP-9 and glyceraldehyde 3-phosphate dehydrogenase (GAPDH) mRNA expression were determined by real-time PCR using the ABI PRISM 7900 sequence detection system and SYBR ${ }^{\circledR}$-Green (Applied Biosystems, Foster City, CA, USA). The primers were: MMP-9 (NM 004994) sense, CCTGGAGACCTGAGAACCAATCT and antisense, CCACCCGAGTGTAACCATAGC, and GAPDH (NM 002046) sense, ATGGAAATCCCATCACCATCTT, and antisense, CGCCCCACTTGATTTTGG. To control for variation in mRNA concentration, the results were normalized to the housekeeping gene, GAPDH. Relative quantitation was performed using the comparative $\Delta \Delta C_{t}$ method according to the manufacturer's instructions.

Preparation of nuclear extract. MCF-7 cells $\left(2 \times 10^{6}\right)$ were treated with RCE in the presence or absence of TPA for $4 \mathrm{~h}$. Cells were immediately washed twice, scraped into $1.5 \mathrm{ml}$ of ice-cold PBS (pH 7.5), and pelleted at 1,500 x g for $3 \mathrm{~min}$. Cytoplasmic and nuclear extracts were prepared from cells using the NE-PER ${ }^{\circledR}$ nuclear and cytoplasmic extraction reagents (Pierce Biotechnology). 
A

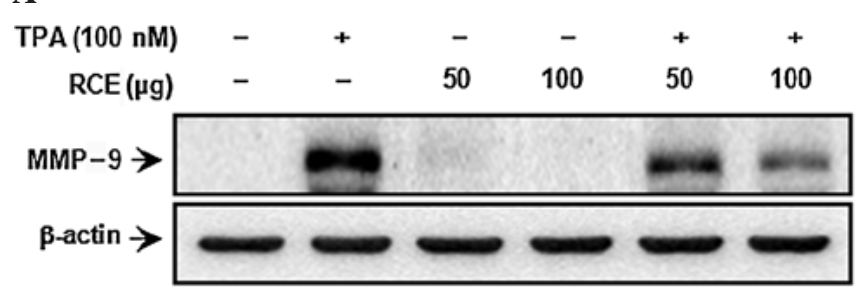

B

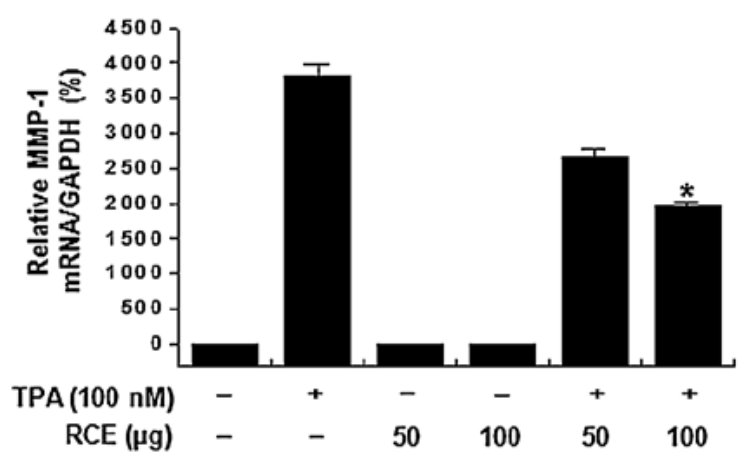

C

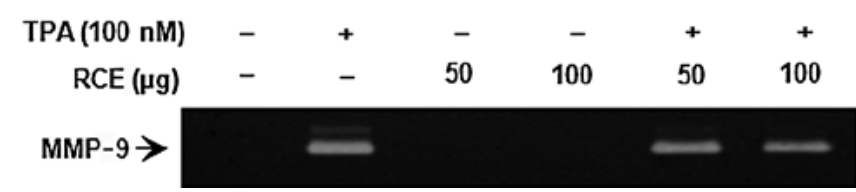

Figure 2. RCE inhibits TPA-induced MMP-9 expression in MCF-7 cells. MCF-7 cells in monolayer were treated with the indicated RCE concentrations in the absence or presence of TPA for $24 \mathrm{~h}$. (A) Cell lysates were analyzed by Western blot analysis with anti-MMP-9. The blot was reprobed with anti- $\beta$-actin to confirm equal loading. (B) MMP-9 mRNA levels were analyzed by real-time PCR and GAPDH was used as an internal control. (C) Conditioned medium was prepared and used for gelatin zymography. Each value is the means \pm SEM of three independent experiments. ${ }^{*} p<0.01$ vs. TPA.

Electrophoretic mobility shift assay (EMSA). NF- $\mathrm{KB}$ activation was assayed with a gel mobility shift assay using nuclear extracts. An oligonucleotide containing the $\mathrm{\kappa}$-chain $(\kappa \mathrm{B}$, 5'-CCGGTTAACAGAGGGGGCTTTCCGAG-3') binding site was synthesized and used as a probe for the gel retardation assay. The two complementary strands were annealed and labeled with $\left[\alpha_{-}{ }^{32} \mathrm{P}\right] \mathrm{dCTP}$. Labeled oligonucleotides $(10,000 \mathrm{cpm}), 10 \mu \mathrm{g}$ of nuclear extracts, and binding buffer [10 mM Tris-HCl, pH 7.6, $500 \mathrm{mM} \mathrm{KCl,} 10 \mathrm{mM}$ EDTA, 50\% glycerol, $100 \mathrm{ng}$ poly (dI·dC), $1 \mathrm{mM} \mathrm{DTT]}$ were then incubated for $30 \mathrm{~min}$ at room temperature in a final volume of $20 \mu 1$. The reaction mixtures were analyzed by electrophoresis on $4 \%$ polyacrylamide gels in $0.5 \mathrm{X}$ Tris-borate buffer. The gels were dried and examined by autoradiography. Specific binding was controlled by competition with a 50 -fold excess of cold $\kappa \mathrm{B}$ oligonucleotide.

Invasion assay. The invasion assay was carried out in 24-well chambers ( $8 \mu \mathrm{m}$ pore size) coated with $20 \mu \mathrm{l}$ Matrigel-diluted DMEM. The Matrigel coating chambers were re-hydrated in $0.5 \mathrm{ml}$ DMEM for $30 \mathrm{~min}$ immediately prior to the experiments. Cells $\left(2 \times 10^{5}\right)$ were added to the upper chamber, with chemoattractant in the bottom well. Conditioned medium

\begin{tabular}{|c|c|c|c|c|c|c|}
\hline TPA (100 nM) & - & + & - & 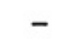 & + & + \\
\hline RCE $(\mu \mathrm{g})$ & - & - & 50 & 100 & 50 & 100 \\
\hline
\end{tabular}

Free probe $\rightarrow$

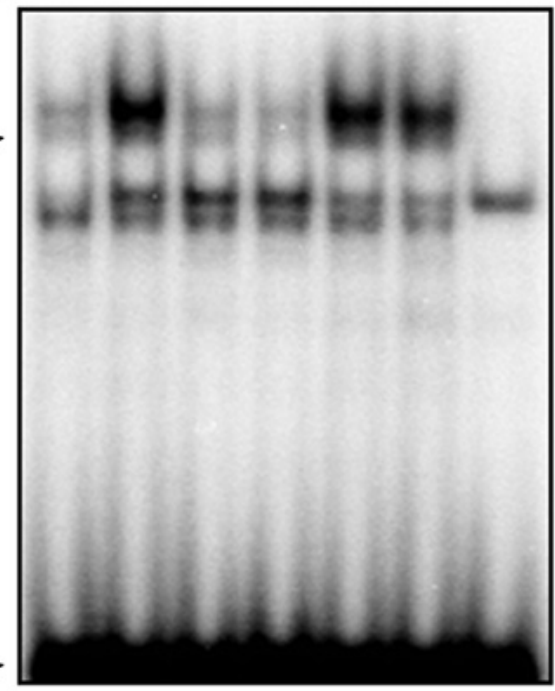

B

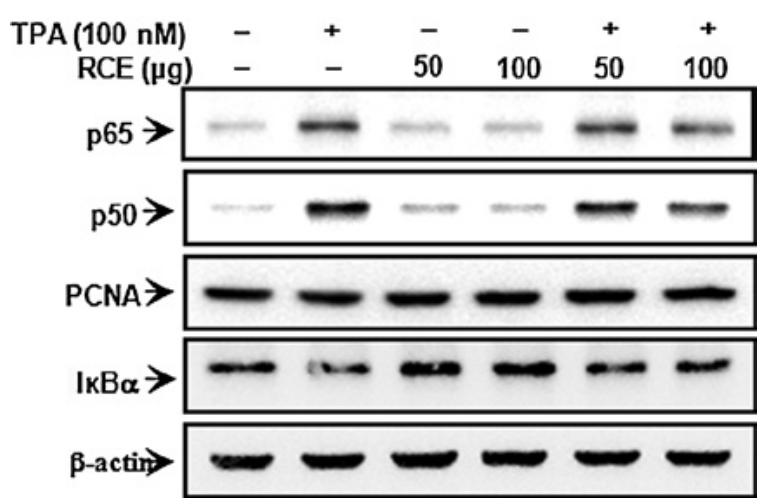

Figure. 3. RCE blocks TPA-induced NF- $\kappa \mathrm{B}$ activation in MCF-7 cells. Cells were treated with RCE in the absence or presence of TPA. Following $3 \mathrm{~h}$ of incubation, nuclear extracts were prepared as described in Materials and methods. (A) NF- $\kappa$ B DNA binding was analyzed by EMSA. (B) The translocation of p65 and p50 to the nucleus and I $\mathrm{B} \alpha \alpha$ degradation in the cytoplasm was determined by Western blotting as described in Materials and methods.

$(0.5 \mathrm{ml})$ was added to the lower compartment of the invasion chamber. The chambers were incubated for $24 \mathrm{~h}$. After incubation, cells on the upper side of the chamber were removed using cotton swabs, and cells that had migrated were fixed and stained with Toluidine blue solution. Invading cells were counted in five random areas of the membrane using a light microscope. Analyzed data are the means \pm SEM from three individual experiments performed in triplicate.

Statistical analysis. Statistical data analysis was performed using ANOVA and Duncan's test. Differences with $\mathrm{p}<0.05$ were considered to be statistically significant.

\section{Results}

Effect of RCE on of MCF-7 cell viability. To investigate the cytotoxicity of RCE on MCF-7 cells, the cells were seeded into 96-well culture plates at a density of $2 \times 10^{4}$ cells/well. The effect of RCE on MCF-7 cell toxicity was analyzed using the 

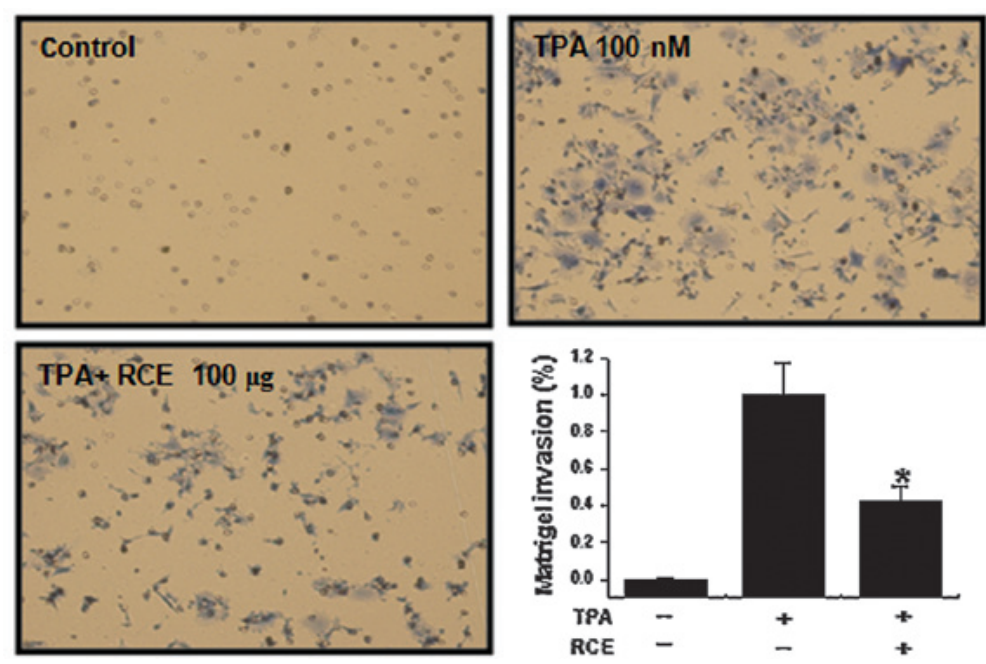

Figure 4. Effect of RCE on TPA-induced Matrigel invasion in MCF-7 cells. Cells were seeded onto the upper chamber and drugs were placed in the well. After $24 \mathrm{~h}$ of incubation, cells on the bottom of the filter were fixed, stained, and counted. Each value is the means \pm SEM of three independent experiments. * $\mathrm{p}<0.01$ vs. TPA.

MTT assay. Treatment of MCF-7 cells with indicated concentrations of RCE for $24 \mathrm{~h}$ did not cause any significant change in cell viability (Fig. 1). Therefore, we performed experiments in optimal non-toxic concentrations (50 and $100 \mu \mathrm{g}$ ) of RCE with no change in morphology.

Effect of RCE on TPA-induced MMP-9 expression in MCF-7 cells. To investigate the effect of RCE on TPA-induced MMP-9 expression, Western blot analysis, real-time PCR, and zymography were performed in MCF-7 cells. Western blot analysis revealed that RCE treatment of MCF-7 cells blocked the up-regulation of TPA-induced MMP-9 protein expression (Fig. 2A). Real-time PCR revealed that TPA increased the MMP-9 expression level in MCF-7 cells, and that RCE blocked TPA-induced MMP-9 up-regulation in a dose-dependent manner (Fig. 2B). Zymography was performed to determine the effect of RCE on TPA-induced MMP-9 secretion. MCF-7 cell treatment with TPA resulted in increased MMP-9 secretion. RCE significantly diminished TPA-induced MMP-9 secretion (Fig. 2C). These results indicate that RCE is a potent inhibitor of TPA-induced MMP-9 expression in MCF-7 cells.

Effect of RCE on TPA-inducedNF- $\kappa B$ DNA binding activity. To clarify the mechanism of RCE-mediated inhibition of MMP-9 expression, the effect of RCE on the TPA-induced activation of NF- $\kappa \mathrm{B}$ was evaluated using EMSA. As shown in Fig. 3A, TPA substantially increased NF- $\kappa B$ binding activity. Treatment with RCE inhibited TPA-stimulated NF- $\mathrm{BB}$ binding activity. $\mathrm{RCE}$ itself had no effect on NF- $\kappa \mathrm{B}$ binding activity. These results indicate that RCE specifically blocks TPA-induced $\mathrm{NF}-\kappa \mathrm{B}$ activation in MCF-7 cells. Under basal conditions, the cytoplasmic protein I $\mathrm{K} \mathrm{B} \alpha$ directly binds to $\mathrm{p} 65$ and p50 subunits and represses their nuclear translocation. Therefore, we determined the alteration of I $\kappa \mathrm{B} \alpha$ levels of the cytoplasmic fraction and p65 and p50 levels of the nuclear fraction in this study. TPA-stimulated MCF-7 cells exhibited a decreased level of I $\mathrm{KB} \alpha$ protein in the cytoplasm and increased levels of $\mathrm{p} 65$ and p50 in the nuclear fraction when compared to a similar fraction in the unstimulated cells. However, the increased
I $\mathrm{B} \alpha$ degradation and translocation of $\mathrm{p} 65$ and $\mathrm{p} 50$, a result of TPA stimulation, was significantly suppressed by treatment with RCE (Fig. 3B).

Effect of RCE on TPA-induced MCF-7 cell invasion in vitro. It has been reported that the up-regulation of MMP-9 expression contributes to the invasion of cancer cells $(19,20)$. An in vitro invasion assay was used to investigate the inhibitory effects of RCE on the invasive potency of breast carcinoma MCF-7 cells. Treatment of TPA increased MCF-7 cell invasion when compared with untreated control cells. Incubation of MCF-7 cells with TPA resulted in a 10.5-fold increase in the invasion of MCF-7 cells. However, treatment with RCE significantly reduced the TPA-induced cell invasion by $82 \%$ (Fig. 4).

\section{Discussion}

Our results show for the first time that RCE suppressed TPA-induced MMP-9 expression by blocking the NF- $\mathrm{KB}$ signaling pathways and that the suppression of MMP-9 expression was well correlated with its inhibition of cell invasion. Previous studies have demonstrated that NF- $\mathrm{kB}$ is a molecular target in RCE treated cells $(15,19)$. Our findings showed the molecular mechanism of RCE, and that RCE blocked the TPA-mediated activation of NF- $\mathrm{KB}$ pathway.

Breast cancer is the leading cause of death from cancer in women worldwide. It is the second most frequent cause of death in women overall in the USA. Metastasis is the primary cause of breast cancer mortality. Tumor metastasis is a multistep process by which a subset of individual cancer cells disseminates from a primary tumor to distant secondary organs or tissues. This process involves cell proliferation, ECM degradation, cell migration, and tumor growth at metastatic sites $(13,15)$. Tumor cell invasion is an early step in the metastatic cascade, representing the beginning of the transition from the benign stage to malignancy. Morphologically, tumor invasion is associated with a distorted edge of the primary tumor where individual or cohorts of tumor cells actively invade the tissue ECM surrounding the primary tumor (20). 
MMP-9 is regarded as a critical molecule in processing tumor invasion and metastasis. MMP-9 activation has been revealed to be particularly associated with tumor progression and invasion, including that of mammary tumors (21). In previous reports, inflammatory cytokines, growth factors, or phorbol esters were revealed to stimulate MMP-9 by activating different intracellular-signaling pathways in breast cancer cells (22-25). The inhibitory effect on MMP-9 expression is crucial for the development of a therapeutic experimental model of tumor metastasis.

$\mathrm{NF}-\kappa \mathrm{B}$ is a transcription factor of significance to the regulation of MMP-9, as the MMP-9 gene promoter contains binding sites for $\mathrm{NF}-\kappa \mathrm{B}(13) . \mathrm{NF}-\kappa \mathrm{B}$ is an inducible dimeric transcription factor that belongs to the Rel/NF- $\kappa \mathrm{B}$ family of transcription factors and consists of two major polypeptides, p65 and p50 (26). NF- $\kappa \mathrm{B}$ is initially located in the cytoplasm in a dormant form complexed with $\mathrm{I} \kappa \mathrm{B}$, an inhibitory factor of NF- $\kappa \mathrm{B}$. Various inducers such as TPA, cytokines and stress can dissociate this complex, presumably by $\mathrm{I}-\kappa \mathrm{B}$ phosphorylation, resulting in the release of $\mathrm{NF}-\kappa \mathrm{B}$ from the complex. $\mathrm{NF}-\kappa \mathrm{B}$ then translocates to the nucleus, where it interacts with specific DNA recognition sites to mediate gene transcription. NF- $\kappa \mathrm{B}$ elements are centrally involved in MMP-9 gene induction by TPA $(15,16)$. Our results reveal that RCE inhibited MMP-9 expression by suppression of $\mathrm{NF}-\kappa \mathrm{B}$ in breast carcinoma cells.

In conclusion, our results have demonstrated that $\mathrm{RCE}$ is a potent inhibitor of TPA-induced MMP-9 expression and markedly blocks the ability of the NF- $\kappa \mathrm{B}$ pathway in breast carcinoma cells. This is the first study revealing RCE suppression of TPA-stimulated cancer cell invasion by inhibiting MMP-9 expression. We also detailed the molecular mechanisms of the NF- $\kappa \mathrm{B}$ pathway in breast cancer cells responsible for this inhibitory effect. Thus, RCE may be a potential candidate for the prevention of breast tumor invasion and metastasis in vivo.

\section{Acknowledgements}

This study was supported by grants from the National Research Foundation of Korea (NRF) funded by the Korean Government (MEST) (no. 2010-0001355) and (M10528010003-05N2801-00310), the Korea Research Foundation (KRF-2009-0076698), Republic of Korea.

\section{References}

1. Lee SH, Jung JB, Kim SY and Chung BC: Determination of phytoestrogens in traditional medicinal herbs using gas chromatography-mass spectrometry. J Nut Biochem 15: 452-460, 2004.

2. Kim EK, Song MY, Hwang TO, et al: Radix clematidis extract protects against cytokine- and streptovzotocin-induced beta-cell damage by suppressing the NF-kappaB pathway. Int J Mol Med 22: 349-356, 2008.

3. Lee YR, Noh NE, Kwon KB, et al: Radix clematidis extract inhibits UVB-induced MMP expression by suppressing the NF- $\kappa$ B pathway in human dermal fibroblasts. Int J Mol Med 23: 679-684, 2009.

4. Eberhardt W, Huwiler A, Beck KF, Walpen S and Pfeilschifter J: Amplification of IL-1 beta-induced matrix metalloproteinase- 9 expression by superoxide in rat glomerular mesangial cells is mediated by increased activities of NF-kappa B and activating protein-1 and involves activation of the mitogen-activated protein kinase pathways. J Immunol 165: 5788-5797, 2000.
5. Jemal A, Murray T, Ward E, et al: Cancer statistics. CA Cancer J Clin 55: 10-30, 2005.

6. Friedel G, Pastorino U, Ginsberg RJ, et al: Results of lung metastasectomy from breast cancer: prognostic criteria on the basis of 467 cases of the International Registry of Lung Metastases. Eur J Cardiothorac Surg 22: 335-344, 2002.

7. Woessner JF Jr: Matrix metalloproteinases and their inhibitors in connective tissue remodeling. FASEB J 5: 2145-2154, 1991.

8. Nakajima M, Welch DR, Belloni PN and Nicolson GL: Degradation of basement membrane type IV collagen and lung subendothelial matrix by rat mammary adenocarcinoma cell clones of differing metastatic potentials. Cancer Res 47: 4869-4876, 1987

9. Saito N, Hatori T, Murata N, et al: A double three-step theory of brain metastasis in mice: the role of the pia mater and matrix metalloproteinases. Neuropathol Appl Neurobiol 33: 288-298, 2007.

10. Castellano G, Malaponte G, Mazzarino MC, et al: Activation of the osteopontin/matrix metalloproteinase- 9 pathway correlates with prostate cancer progression. Clin Cancer Res 14: 7470-7480, 2008.

11. Kanayama H: Matrix metalloproteinases and bladder cancer. J Med Invest 48: 31-43, 2001.

12. Lin CW, Hou HW, Shen SC, et al: Quercetin inhibition of tumor invasion via suppressing PKC delta/ERK/AP-1-dependent matrix metalloproteinase-9 activation in breast carcinoma cells. Carcinogenesis 29: 1807-1815, 2008.

13. Lee SO, Jeong YJ, Kim M, Kim CH and Lee IS: Suppression of PMA-induced tumor cell invasion by capillarisin via the inhibition of NF-kappaB-dependent MMP-9 expression. Biochem Biophys Res Commun 366: 1019-1024, 2008.

14. Nabeshima K, Inoue T, Shimao Y and Sameshima T: Matrix metalloproteinases in tumor invasion: role for cell migration. Pathol Int 52: 255-264, 2002.

15. Chung TW, Moon SK, Chang YC, et al: Novel and therapeutic effect of caffeic acid and caffeic acid phenyl ester on hepatocarcinoma cells: complete regression of hepatoma growth and metastasis by dual mechanism. FASEB J 18: 1670-1681, 2004.

16. Hong S, Park KK, Magae J, et al: Ascochlorin inhibits matrix metalloproteinase-9 expression by suppressing activator protein1-mediated gene expression through the ERK1/2 signaling pathway: inhibitory effects of ascochlorin on the invasion of renal carcinoma cells. J Biol Chem 280: 25202-25209, 2005.

17. Woo MS, Jung SH, Kim SY, et al: Curcumin suppresses phorbol ester-induced matrix metalloproteinase- 9 expression by inhibiting the PKC to MAPK pathways in human astroglioma cells. Biochem Biophys Res Commun 335: 1017-1025, 2005.

18. Bradford MM: A rapid and sensitive method for the quantitation of microgram quantities of protein utilizing the principle of protein-dye binding. Anal Biochem 72: 248-254, 1976.

19. Chambers AF and Matrisian LM: Changing views of the role of matrix metalloproteinases in metastasis. J Natl Cancer Inst 89: 1260-1270, 1997.

20. Stetler-Stevenson WG, Hewitt R and Corcoran M: Matrix metalloproteinases and tumor invasion: from correlation and causality to the clinic. Semin Cancer Biol 7: 147-154, 1996.

21. Deryugina EI and Quigley JP: Matrix metalloproteinases and tumor metastasis. Cancer Metastasis Rev 25: 9-34, 2006.

22. Scorilas A, Karameris A, Arnogiannaki N, et al: Overexpression of matrix-metalloproteinase-9 in human breast cancer: a potential favourable indicator in node-negative patients. Br J Cancer 84: 1488-1496, 2001.

23. Cho HJ, Kang JH, Kwak JY, et al: Ascofuranone suppresses PMA-mediated matrix metalloproteinase-9 gene activation through the Ras/Raf/MEK/ERK- and Ap1-dependent mechanisms. Carcinogenesis 28: 1104-1110, 2007.

24. Kajanne R, Miettlinen P, Mehlem A, et al: GF-R regulates MMP function in fibroblasts through MAPK and AP-1 pathways. J Cell Physiol 212: 489-497, 2007.

25. Srivastava AK, Qin X, Wedhas N, et al: Tumor necrosis factor-alpha augments matrix metalloproteinase-9 production in skeletal muscle cells through the activation of transforming growth factor-beta-activated kinase 1 (TAK1)-dependent signaling pathway. J Biol Chem 282: 35113-35124, 2007.

26. Thanos D and Maniatis T: NF-kappa B: a lesson in family values. Cell 80: 529-532, 1995. 